\title{
ESCUELAS Y ESCOLARES. EDUCACIÓN ELEMENTAL EN LA VILLA Y TIERRA DE PADRÓN A FINALES DEL ANTIGUO RÉGIMEN
}

\author{
Ana María Sixto Barcia \\ Universidade de Santiago de Compostela
}

\begin{abstract}
RESUMEN: En el presente estudio hemos realizado un análisis del tema de la instrucción primaria, más conocida como enseñanza de primeras letras, en la comarca del Bajo Ulla durante los siglos XVIII y XIX. Después de comprobar el avance lento pero constante de la presencia escolar, nos hemos ocupado de aquellos aspectos relativos a la calidad de la educación tales como las condiciones y capacidades de los maestros, los métodos y el sistema utilizado, los horarios y el calendario escolar, el local destinado para tal fin y el material empleado en la enseñanza.
\end{abstract}

Palabras clave: enseñanza de primeras letras, educación, aprendizaje, escuelas, maestros de instrucción primaria, siglo XVIII, siglo XIX, Antiguo Régimen, Padrón, Galicia.

ABSTRACT: In the present study we have made an analysis of the subject of the primary instruction, better known as education of first letters, in the region of the Low Ulla during the XVIII and XIX centuries. After verifying the slow but constant advance of the school presence, we have analyzed those aspects related to the quality of teaching such as the conditions and capacities of the teachers, the methods and the system used, the schedules and the school calendar, the buildings destined to such aim and the materials used in the teaching learning process.

Keywords: education of first letters, teaching, learning process, schools, primary instruction teachers, XVIII century, XIX century, Ancient Regime, Padrón, Galicia.

LA HISTORIA de la Cultura ha experimentado en los últimos años un desarrollo positivo en el marco de los estudios comarcales, locales y provinciales ${ }^{1}$, por la extraor-

1 En lo que a educación y alfabetización se refiere: REY CASTELAO, O.: "Niveles de alfabetización en la Galicia de fines del Antiguo Régimen", Lisants et lecteurs en Espagne, XVe-XIXe. ss, no monográfico de Bulletin Hispanique, 100, 2, 1998, pp. 271-311. SANZ GONZÁLEZ, M.: "Alfabetización y 
dinaria utilidad de la acumulación densa para corregir y completar los estudios de carácter global. En el presente artículo hemos intentado llevar a cabo un acercamiento a la historia cultural y, en concreto, una aproximación a la red escolar y a las características de la educación primaria. Nos planteamos un estudio del siglo XVIII y su evolución hasta el XIX, con el fin de obtener una visión más amplia del panorama educativo a finales de la Época Moderna y en el tránsito a la Contemporánea, así como, la reconstrucción del mapa escolar, analizando su evolución cronológica y, al mismo tiempo, conociendo la calidad y los métodos de la enseñanza. Esta primera presentación de conclusiones deberá ser completada más adelante con un acercamiento a las tasas de alfabetización y analfabetismo para comprobar la efectividad o, por el contrario, la deficiencia instructiva de la zona. El marco geográfico del estudio abarca los actuales ayuntamientos de Dodro, Padrón, Rois, Rianxo y Teo que, a su vez, comprenden unas 38 parroquias y aúnan un total de $322 \mathrm{~km}^{2}$. El Bajo Ulla es una zona de gran diversificación económica que permite conjugar urbanidad con ruralidad, por lo que su cosmovisión oscilaría indudablemente entre ambos mundos como resultado de las dependencias existentes entre uno y otro.

Las fuentes documentales básicas que hemos utilizado para la realización del trabajo son, en primer lugar, para inicios del XVIII, el Padrón Calle Hita (1708), y para mediados, el Catastro del Marqués de la Ensenada (1753), que permiten localizar escuelas y/o maestros; en segundo lugar, en el XIX, los diccionarios estadísticos y entre ellos, el de Pascual Madoz ${ }^{2}$ y los Estados Escolares de 1862 y $1876^{3}$. Asimismo, la documentación, de índole eclesiástica ${ }^{4} \mathrm{y}$ de carácter municipal ${ }^{5}$, nos ha facultado para completar cualitativamente muchos de los aspectos obtenidos en las de carácter fiscal.

escolarización en Galicia a finales del Antiguo Régimen", Obradoiro de Historia Moderna, 1, 1998, pp. 229-249. SANDOVAL VEREA, F.: "Alfabetización, familia y patrimonio en la Galicia rural: la comarca de Ordes, 1588-1860”, Obradoiro de Historia Moderna, 9, 2000, pp. 211-233. REY CASTELAO, O.: “Alfabetización y red escolar de A Estrada, siglos XVIII-XIX”. A Estrada: Miscelánea histórica y cultural, 6, 2003, pp. 91-104. SAAVEDRA, P. y SOBRADO CORREA, H.: El siglo de las luces: cultura y vida cotidiana, Síntesis, Madrid, 2004, pP. 108-136. SUAREZ GOLÁN, F.: "Escuelas y cátedras en el centro de Galicia (ss. XVIII y XIX)" en GARCÍA HURTADO, M.-R. (coord.): El futuro de las humanidades, Betanzos, 2007, pp. 15-22.

2 Madoz, P.: Diccionario Geográfico-estadístico-histórico de España y sus posesiones de Ultramar, Madrid, 1845-50.

3 Archivo Histórico Universitario de Santiago. (AHUS). F.U. Ensino Primario, Caja 28, Porción $3^{\circ}$, P. $1,2,3,4,5,6,7,8,9,10,11,12,13,14,15,16,17,18,19,20,21$. AHUS. F.U. Ensino Primario, Caja 28, Porción $6^{\circ}$, P. 1, 2, 3, 4.

4 Archivo Histórico Diocesano de Santiago (AHDS), Serie, Visitas Pastorales: leg. 1262, 1264, 1265, 1276/1, 1276/2. AHDS, Serie, Instrucción Pública, leg. 456, 459, 460.

5 Archivo Municipal de Padrón (AMP), Sección, Educación, leg. 497, 498, 500, 501, 502, 503, 504, 595. AHUS, F. U. Ensino primario, caja 28, porción 3a , Ayuntamiento de Dodro, folios 1-2. AHUS, F.U. Ensino primario, caja 28, porción $3^{\text {a }}$, Ayuntamiento de Padrón, folios 1-3. AHUS, F. U. Ensino primario, caja 28, porción $3^{\mathrm{a}}$, Ayuntamiento de Rianxo, folios 1-4. AHUS, F. U. Ensino primario, caja 28, por- 
Nuestra investigación se ha centrado, en su primera fase, en los medios de adquisición del aprendizaje cultural básico o formación elemental infantil. Esta cuestión ha sido abordada desde dos perspectivas metodológicas, una cuantitativa, a través de la cual hemos reconstruido la red escolar y, otra cualitativa, indicada para el análisis de las características de la docencia en el área estudiada.

\section{La red escolar}

Diversos trabajos que se han ocupado del estudio de la red escolar gallega y de su medición estadística han documentado una malla docente poco densa e inestable, cuyas condiciones pedagógicas presentaban un carácter paupérrimo ${ }^{6}$. Nuestra intención era comenzar el estudio a inicios del siglo XVIII, sirviéndonos para ello de los datos aportados por el Padrón Calle Hita, pero la consulta de esta fuente -empleada con éxito en otros trabajos- no nos ha proporcionado ningún dato significativo, por lo que hemos tenido que prescindir de la primera cata prevista ${ }^{7}$. En el Catastro de Ensenada ${ }^{8}$ hemos sondeado la presencia de maestros o individuos que se pudieran haber dedicado a la instrucción. Ha resultado muy complejo deducir y distinguir, por el propio carácter de la fuente ${ }^{9}$, entre un maestro profesional de aquel que no lo era, o del que estaba medianamente alfabetizado y utilizaba la labor docente como complemento de su economía. Obtenemos para 1753 un 34,2\% de presencia escolar, una cifra muy superior a otras estimaciones $^{10}$, lo que responde a un contexto socio-económico favorable ${ }^{11}$, que per-

ción $3^{\mathrm{a}}$, Ayuntamiento de Rois, folio 1. AHUS, F. U. Ensino primario, caja 28, porción $3^{\mathrm{a}}$, Ayuntamiento de Teo, folios 1-3.

6 REY CASTELAO, O.: Op. cit. , SANZ GONZÁlEZ, M.: Op. cit., SOBRADO CORREA, H., SAAVEDRA, P.: Op. cit. , SANDOVAL VEREA, F.: Op. cit., SUÁREZ GOLÁN, F.: Op. cit. etc.

7 Debemos hacer referencia a las conclusiones de M. Sanz para el área S. O. de Galicia, dónde constataba que un $11,7 \%$ de las parroquias al sur del río Ulla contaban con presencia docente a principios del XVIII. En 1708 la red escolar todavía se mostraba incipiente en el interior con un 6.8\% según las conclusiones de F. Suárez Golán. SANZ GONZÁLEZ, M.: Op. cit., p. 234. SUÁREZ GOLÁN, F.: Op. cit., p.15.

8 Archivo del Reino de Galicia (ARG), Catastro de La Ensenada, Interrogatorio, Libros Personales (Legos y Eclesiásticos) y Libros Reales (Legos y Eclesiásticos), libros 241, 242, 243, 244, 245, 246, 248, 251, 252, 253, 254, 255.

9 El Catastro de la Ensenada presenta ciertas limitaciones para el estudio de la Educación, pues es una fuente cuyo interés es eminentemente fiscal, por lo que excluye a aquellas personas que, de una forma más o menos desinteresada, irregular o informal, se podrían haber dedicado a la alfabetización de niños. Del mismo modo, los datos no fueron recogidos ni con la misma pulcritud, ni con el mismo detalle en todas las áreas, por lo que las informaciones son desiguales.

10 En 1753 se calculaba una tasa de un 17\% para Pontevedra -M. Sanz-, obteniendo para A Estrada -O. Rey- unas cifras más bajas. En cambio, en la Galicia interior-F. Suarez-las cifras todavía eran más bajas, en tierras arzuanas suponían un 12.4\%. SANZ GONZÁLEZ, M.: Op. cit., p. 235. REY CASTELAO, O.: "Alfabetización...", p. 97. SUÁREZ GOLÁN, F.: Op. cit., p.15.

11 Durante el siglo XVII y hasta la segunda mitad del XVIII se producirá un crecimiento económico, inducido, en parte, por los cambios provocados por la introducción y expansión del maíz y por un aumento en la producción vitícola. 
mitió la proliferación y el mantenimiento de actividades relacionadas con la formación -infantil y adulta-. En cuanto a la población sobre la que la red se distribuía, había en 1753 un total de 7.908 vecinos, por lo que se contabilizaba un maestro por cada 376,6 familias, lo que, en definitiva, nos indica una cifra muy baja ${ }^{12}$.

La base económica del valle del Ulla estaba regida por la producción agrícola, cerealera y vitícola, acompañada de una incipiente protoindustria textil basada en la producción local del lino y en la importación de esta fibra. La existencia de una economía rica es un factor que permite localizar una elevada presencia de maestros, pues indica la posibilidad de un aumento de la inversión en la educación de los niños. Si a nivel económico la división o distinción entre el interior y la costa no ha sido necesaria porque se trata de una zona muy próxima al mar y porque su productividad es análoga, no ocurre lo mismo en cuanto a la localización de la red escolar. Se observa una mayor concentración hacia la zona nororiental, debido no sólo a sus circunstancias económicas, sino también porque era el área era más sensible a la atracción que Santiago, como centro difusor y generador de cultura, ejerció sobre su entorno. La diversificación económica de las zonas próximas a la costa y la pesca, sector en el que se ocupaba gran parte de la población, podría ser la causa de una mayor implicación laboral del niño, por ello, hasta mediados del XIX estas zonas presentaron una cierta relajación en las labores educativas. El actual ayuntamiento de Teo era el que ostentaba una más elevada concentración de maestros, ya que en sus tierras albergaba el 38,46\% de las escuelas. La villa de Padrón y la villa de Rianxo contaron desde temprano con una presencia escolar auspiciada y amparada por el municipio, aunque la villa de Padrón destacaba con sus tres escuelas, una de las cuales era sufragada completamente por el poder municipal, mientras que, la villa de Rianxo sólo gozaba de una ${ }^{13}$. Las zonas más productivas y las mejor comunicadas, así como las más pobladas, eran las de mayor presencia educativa, pues un maestro a la hora de asentarse tendría en cuenta estas circunstancias, aunque también nos encontramos con excepciones, como en el caso de pequeñas feligresías de menor riqueza que contaban con escuela debido generalmente a la existencia de una fundación. A pesar de su vecindario reducido, Baamonde -64 vecinos-, Teo -129 vec.- y Sorribas -156 vec.- disponían de un docente, lo que nos indica la existencia de una fundación que se habría

12 La mayor parte de las feligresías con presencia docente contaban con una población que oscilaba entre los 200 y los 400 vecinos.

13 La explicación se podría deber a diversos factores, si bien por ser zona costera se podría requerir una mayor contribución del niño en las labores de la casa, o porque en el interrogatorio no se incluyeran todas las escuelas, etc, pero nos inclinamos a pensar que, aún siendo villa, su pobreza era la razón fundamental de esta deficiencia. 
establecido sin tener en cuenta el dato demográfico, sino otras consideraciones como el origen o la residencia del fundador ${ }^{14}$.

La segunda cata la hemos realizado a mediados del siglo XIX y la fuente utilizada ha sido el Diccionario de Pascual Madoz. El documento reproduce una información bastante homogénea para el territorio seleccionado aunque presenta una serie de limitaciones ${ }^{15}$. En los casi cien años que separan estas dos muestras se han producido una serie de modificaciones de diversa índole, entre ellas, en 1834 tuvo lugar una reforma administrativa y territorial del país, que originó una nueva organización del territorio. Los cambios no sólo afectaron a la denominación o al número de feligresías, sino también a la desaparición de los señoríos, por tanto, el número de entidades manejadas se ve alterado, aunque no su espacio físico. El contexto político de inicios del XIX y la inestabilidad de los primeros años del reinado de Fernando VII, trajeron consigo una inseguridad que influyó en el devenir de sus gentes ${ }^{16}$.

En 1846 la presencia escolar era de un 53,8\%, lo que supone un crecimiento significativo ${ }^{17}$, aunque, a la luz de los datos, todavía no se puede hablar de un cambio en la calidad de la educación, pues en su mayoría, las escuelas siguieron teniendo caracteres arcaicos. La villa y tierra de Padrón contaba con más de 6.700 vecinos, por lo que había un maestro por cada 295,6 familias. Se puede apreciar un aumento considerable de la presencia escolar, pues hacia 1753 localizábamos un maestro por cada 376,6 familias, aunque las cifras siguen siendo bajas.

14 Por ejemplo, Jacobo Llorente, residente en Pontevedra paga un real al día por cada niño al maestro Domingo de la Iglesia. AHUS. Catastro de La Ensenada, Interrogatorio, Libro 254, folio 187.

15 Sus problemas ya han sido planteados y cuestionados con anterioridad por otros autores como Rey Castelao o Sanz González. En el Diccionario Geográfico-estadístico-histórico de España y sus posesiones de Ultramar de P. Madoz no coincide el número de escuelas que se ofrece en la información general del Partido con los datos aportados por cada feligresía. Rey Castelao, O.: Libros y lectura en Galicia. Santiago, 2003, p. 52.

16 La inseguridad y la inestabilidad actuaron de modos muy diversos sobre la población ocasionando reacciones muy desiguales como el cierre de escuelas. En este sentido, algunos notarios ante la preocupación decidieron enterrar en arcas los documentos que custodiaban: "Viva la independencia de la nación?, España ya es libre por el denuedo de nuestras tropas. Este y varios protocolos se hallaron por unos meses enterrados en un arca, cuando las tropas francesas invadieron nuestra provincia de Galicia, a pesar de la preservación que se le pudo hacer en épocas tan apretadas, pasó la humedad y es la causa de algunas hojas carcomidas. Lo que se anota para la posteridad." AHUS. Sección, Protocolos notariales Padrón, 1750, José Ramón Penas Baamonde, folio 154.

17 Un crecimiento que podría ser mayor según afirma N. de Gabriel, quien ha defendido que el Diccionario de Madoz no recoge la realidad escolar gallega, pues es estos años las escuelas más habituales en el ámbito gallego fueron las denominadas de ferrado y su localización fue compleja. Gabriel, N. de: "Escolantes e escolas de ferrado". Sarmiento, 3, 1999, p. 93-132. 
El núcleo de Padrón siguió destacando a mediados del XIX sobre las demás entidades, los ayuntamientos de Rianxo y Dodro aumentaron su influencia ${ }^{18}$, por lo que se aprecia una expansión que no sólo afectó a las tradicionales áreas educativas, sino que se extendió o afectó a las zonas de costa que habían jugado un papel secundario a mediados del XVIII. El Ayuntamiento de Rois fue el que experimentó el principal despegue, no tanto a nivel numérico, pues pasó de cinco a ocho escuelas, sino por su dispersión. En definitiva, no sólo se ha producido un aumento en el número de escuelas, sino que también ha tenido lugar una expansión escolar ${ }^{19}$, se aprecia una notable difusión entorno a la franja norteña. A pesar de este incremento, algunas entidades han interrumpido su tradición docente ${ }^{20}$. Los motivos podrían estar relacionados con el hecho de que en el Antiguo Régimen la tradición formativa del mundo rural dependía de un individuo: el maestro. En ocasiones, la desaparición del mismo podía provocar el fin de la escolarización en un determinado lugar, si bien en otras el escolante se encargaba de adiestrar a uno de sus discípulos, quien tomaba el relevo generacional y continuaba así la tradición escolar. A ello debemos sumarle el propio contexto de principios de siglo, que habría provocado una relativa inestabilidad que podría haber influido en la escolarización. La presencia educativa suponía un coste añadido y la existencia de una crisis económica habría creado la necesidad de reconducir el excedente hacia la alimentación, el vestido, la vivienda, etc. De todos modos, es necesario matizar esta afirmación ${ }^{21}$, dado que la incorporación de nuevas entidades a la red docente vendría dada por un mayor interés de los padres y por una notable actividad fundacional ${ }^{22}$. En cambio, sí podemos advertir una ralentización del crecimiento de la instrucción primaria en la década de los 60, aunque con la Restauración se recuperó el crecimiento y la restitución de escuelas que hubieron de desaparecer en el periodo anterior.

Los estados escolares nos han proporcionado una cantidad ingente de datos y cifras que nos posibilitan a plantear un aumento considerable de la red escolar cuya tasa era del 71,1\% en 1876. Parejo al incremento numérico, fue la dispersión de la malla docente, que consigue un desarrollo muy notable en Rois y Padrón, ayunta-

18 Aparecen recogidas en el Diccionario de Madóz cinco escuelas en el Ayuntamiento de Rianxo y tres en el de Dodro.

19 Esta expansión se hace más efectiva en a la década de los 50, fecha en la que constatamos una tasa de un 60,5\%. AMP, Sección, Educación, leg. 500.

20 Baamonde, Cruces y Reyes han interrumpido su tradición educativa.

21 Asados, Buján, Dodro, Herbogo, Hermédelo, Leiro, Leroño, Luou y Teo, se incorporaron a mediados del siglo XIX a las parroquias con presencia docente.

$22 \mathrm{El}$ aumento y la dispersión territorial de la red escolar fue algo común para el área gallega. La tasa de escolarización para Pontevedra fue de un 31,46\%, en A Estrada las cifras ascienderon a un 51\%, mientras que en Arzúa, Sobrado y Melide alcanzaron un 38,6\%. SANZ GONZÁLEZ, M.: art. cit., p. 234. REY CASTELAO, O.: Ibídem, p. 99. SUÁREZ GOLÁN, F.: Op. cit, p. 16. 
mientos que superan el $75 \%$ de presencia escolar en sus feligresías, mientras que Dodro, Rianxo y Teo superan el 65\%.

Los emigrantes fueron precoces en su preocupación por la educación infantil y sus dotaciones para la creación de centros educativos fueron comunes en toda Galicia. Los indianos al llegar a nuevas tierras fueron conscientes de la importancia de saber leer y escribir, así constituyeron escuelas en sus lugares de origen²3 -"para sacar a los hombres de malas mañas, se crea una escuela para enseñar a los niños a leer, escribir, contar y demás cosas necesarias"24_. La etapa de mayor ímpetu fundacional registró sus mayores esfuerzos entre la segunda mitad del XVIII y la primera del XIX ${ }^{25}$. Si este espíritu era poco relevante entorno a 1753, no podemos obviar la existencia de nuevas dotaciones a mediados del XIX, a pesar de que los padres siguieron siendo los principales filántropos de la educación infantil. Según los Estados Escolares la mayoría de los padres $-67,7 \%$-, exceptuando a aquellos pertenecientes al estatuto de pobreza, contribuyeron activamente, junto al poder local, en el mantenimiento de los centros escolares y de sus maestros. El avance de la enseñanza pública se hace patente a partir de 1857, lo que provoca un receso de la educación privada, "lo primero que llama la atención es la dinámica contrapuesta que siguen escuelas públicas y privadas, ya que cuando las primeras avanzan, las segundas retroceden, y viceversa" ${ }^{26}$. A diferencia de la etapa anterior, entre 1867 y 1876, el número de escuelas públicas de financiación mixta aumenta hasta situarse en un 95,2\%, lo que termina con la tradición escolar existente, tradición que en cierto modo se recuperó en las dos últimas décadas del siglo XIX.

\section{Escuelas, maestros y escolares}

Uno de los aspectos más relevantes del estudio de la escolarización deriva de su régimen de financiación. A mediados del siglo XVIII solamente el 10\% de los sueldos de los maestros eran sufragados por el erario público, siendo los padres y,

23 "Entre los de índole común y permanente, cabe señalar una estimación valorativa de signo positivo respecto a la enseñanza y a sus potencialidades; estimación que proviene de una apetencia de cultura, dimanante, a su vez, bien de las propias carencias personales que aspiran a ser subsanadas en futuras generaciones (...)". PEÑA SAAVEDRA, V.: Éxodo, organización comunitaria e intervención escolar: la impronta educativa de la emigración transoceánica en Galicia. A Coruña, 1991, p. 324.

24 Fundación creada en Luou en 1825 por D. José Vidal y Vidal emigrado en Buenos Aires. AHDS, Serie, Instrucción Pública, leg. 459.

25 El 28,5\% de las fundaciones se realizaron antes de 1750 frente al 71,4\% que se produjo entre 1750 y 1850 , registrándose el mayor apogeo en la segunda mitad del XIX con un 58\% sobre el total.

26 GABRIEL, Narciso de: Leer, escribir y contar: Escolarización popular y sociedad en Galicia (1875-1900), Sada, 1990, p.142. 
en contadas ocasiones, los fundadores los encargados de costear y amparar la educación elemental de sus gentes. Según los datos aportados por la Estadística de 1846 en el Partido Judicial de Padrón, el 76,9\% eran escuelas privadas, frente al 23,1\% de las "públicas". A pesar del manifiesto interés municipal por reformar y extender la enseñanza -"El Partido Judicial de Padrón no es el que más abandonado tiene en la Provincia de la Coruña, el importante ramo de la instrucción primaria, pues nos consta que se están realizando importantes esfuerzos para mejorarla y que desaparezcan las escuelas y encargados de enseñanza sin título (...)”-, el costo educativo recayó fundamentalmente en la financiación privada. Por el contrario, desde 1858 se produjo un cambio significativo en lo que se refiere a la educación pública ${ }^{27}$-de financiación municipal-, pues pasó de un $10 \%$ en 1753 a un nada despreciable $28 \%$ en $1846^{28}$. Aunque debemos matizar estas cifras, puesto que este incremento no se tradujo en un aumento del numero de escuelas, sino que mostraba un mayor intervencionismo municipal al pasar a controlar las escuelas de iniciativa privada: fundaciones y escuelas de emigrantes. A partir de la segunda mitad del XIX el poder municipal se involucró activamente en el desarrollo escolar, tal y cómo lo establecía la ley de Instrucción Pública de 9 de septiembre de 1857. Los Estados Escolares de 1862 muestran una mayor participación y vigilancia del poder local, en el control y desarrollo educativo de las escuelas del Ulla. Aunque en muchos casos, su intervención se limitaba a la entrega de la dotación anual y a una somera vigilancia por parte de las Juntas Locales de primera enseñanza. En este sentido, se hacen patentes las reiteradas denuncias expuestas por el inspector Antonio de la Iglesia ante la escasa atención prestada por la Junta Local al estado y desarrollo escolar ${ }^{29}$. En las diversas visitas realizadas por los inspectores de la Junta Provincial de Instrucción Pública ${ }^{30}$ se pusieron de manifiesto las deficiencias de la enseñanza infantil y en las sesiones de Juntas locales, la denuncia y la preocupación de los visitadores por la falta de acomodo, de proyecto educativo y de desarrollo de las escuelas elementales se hizo patente. La dotación personal de los maestros y la del material fue tremendamente oscilante ${ }^{31}$ aunque por

27 A partir de 1858 las escuelas de fundación pasaron a engrosar las filas de las escuelas municipales, por lo que su supervisión y control, desde entonces, pasó a ser competencia de los poderes locales.

28 AMP, Sección, Educación, leg. 497, 498, 499.

29 AHUS. F.U. Ensino Primario, Caja 28, Porción 3a, Ayto. de Dodro, folios 1-2. AHUS. F.U. Ensino Primario, Caja 28, Porción 3a , Ayto. de Padrón, folios 1-3. AHUS. F.U. Ensino Primario, Caja 28, Porción $3^{\mathrm{a}}$, Ayto. de Rianxo, folios 1-4. AHUS. F.U. Ensino Primario, Caja 28, Porción 3 ${ }^{\mathrm{a}}$, Ayto. de Rois, folio 1. AHUS. F.U. Ensino Primario, Caja 28, Porción 3a , Ayto. de Teo, folios 1-3.

30 El inspector de la Junta Provincial de Instrucción Pública de la década de los 60 fue Antonio de la Iglesia y en la década de los 70 lo sustituyó Agustín Rubio Durán.

31 La cantidad percibida por los maestros del bajo Ulla oscilaban entre 4400 reales que percibía el maestro de la escuela elemental completa y ampliada de Padrón a los 1000 rs. que percibía el maestro de la escuela elemental incompleta de niños de Laiño. Ocurre lo mismo con las dotaciones para material 
término medio podríamos establecer que la remuneración del instructor era de unos 1603 reales y la del material era de 427 rs. por término medio en 1862.

La educación del siglo XIX, muy influenciada por la iglesia católica, otorgó a la mujer un papel secundario ${ }^{32}$, por lo que su instrucción, ya fuera pública o privada no iba encaminada a formar mujeres académicas ${ }^{33}$, sino a proporcionar cualidades complementarias a las futuras madres y esposas. El proveer de someros rudimentos de lectura, escritura y aritmética, así como la iniciación en las labores del hogar eran los principales objetivos de la educación elemental femenina, por tanto, ésta careció de la función social atribuida a la masculina ${ }^{34}$. La instrucción infantil presentaba unos caracteres eminentemente masculinos, según el Madoz la asistencia escolar masculina era del $84.8 \%$, frente a un $15,2 \%$ de asistencia femenina ${ }^{35}$. Las cifras concuerdan con la media gallega que contabilizaba en un $85.9 \%$ la asistencia masculina y en un $14.1 \%$ la femenina, aunque difieren someramente de la media provincial $-81.7 \%$ de niños, frente $18,27 \%$ de niñas-. Los niños, no las niñas, acudían preferentemente a la escuela, en parte, porque la enseñanza femenina comportaba un mayor coste-oportunidad para la familia ${ }^{36} \mathrm{y}$, porque como ya hemos dicho, en el Antiguo Régimen, el hombre era el protagonista de la sociedad. Según la Estadística de 1846, en los cinco ayuntamientos que componen el Partido Judicial de Padrón, había tres escuelas públicas completas - dos de niños y una de niñas-, tres escuelas incompletas de niños

de la escuela que podía ir desde los 1100 rs. que percibía la ya nombrada escuela de Padrón a los 250 de la escuela de Laiño. AHUS. F.U Ensino Primario, Caja 28, Porción 3 ${ }^{\mathrm{a}}$, P.4: Padrón, folio 1-4. AHUS. F.U Ensino Primario, Caja 28, Porción 3ª, P.2: Laiño, folio 1-3.

32 "En todo pueblo de 500 almas habrá necesariamente una escuela pública elemental de niños, y otra, aunque sea incompleta, de niñas (...)”. Ley de Instrucción Pública de 9 de septiembre de 1857, artículo 100 .

33 Aunque existieron defensores de la capacidad de la mujer para el estudio de las letras y las ciencias como Fray Luis de Olot: "el espíritu de las mujeres es tan capaz de aprender las ciencias como los hombres”. OLOT, Fray Luis de: Tratado del Origen, y Arte de Escribir Bien: Ilustrado con veinte y cinco láminas. Gerona: Imprenta de Francisco Oliva, 1766, p. 24.

34 "El fin de la instrucción será, pues, la perfección del hombre en orden a sí mismo, a la comunidad, a la naturaleza y a Dios: en relación a sí mismo, instrucción significa perfección y felicidad individual; en cuanto a la comunidad, progreso y prosperidad nacional o felicidad del estado; en orden a la naturaleza, mayor conocimiento y mayor aprovechamiento de los recursos, que aquella le brinda; y, finalmente la instrucción conduce al hombre al destino que el creador le ha reservado". CAPITÁN DÍAZ, A.: Historia del pensamiento pedagógico en Europa: desde sus orígenes al precientifismo pedagógico de J. F. Herbart, Madrid, 1984, p.686.

35 En 1804 asistían el 84,8\% de niños frente al 10,5\% de niñas. La diferencia en estos cuarenta años no se muy significativa aunque se advierte un ligero aumento de la educación femenina. Labrada, L.: Descripción económica del reino de Galicia, Vigo, 1971, p. 62

36 En el domicilio gallego la mujer era una pieza esencial, pues no sólo compartía las tareas agrícolas y ganaderas con el hombre, sino que además se ocupaba del cuidado de la casa, así como de la protección de ancianos e infantes. Del mismo modo, en la tierra del Ulla, la mujer ocupó un papel fundamental en la industria textil, al igual que en actividades relacionadas con la salazón y el transporte del pescado. 
y veinte escuelas privadas mixtas. En 1876 había siete escuelas elementales completas -seis de niños y una de niñas-, ocho escuelas elementales incompletas de niños, cinco escuelas incompletas de niñas, nueve escuelas elementales incompletas mixtas y una escuela privada mixta. En estos treinta años se ha producido un importante avance de la escuela pública, aunque, en lo que a la alfabetización femenina se refiere, esta siguió siendo superada con creces por la masculina.

Si desigual era el número de escuelas masculinas y femeninas, diferente fue también el programa educativo. La ley Moyano estableció que el currículo masculino de la primera enseñanza elemental debía $\operatorname{cursar}^{37}$ : Doctrina cristiana y nociones de Historia Sagrada, lectura y escritura, principios de gramática castellana, principios de aritmética y breves nociones de agricultura, industria y comercio, según las localidades. Y el programa de instrucción primaria superior ${ }^{38}$, además de la prudente ampliación de las materias ya mencionadas, debía desarrollar principios de geometría, dibujo lineal y agrimensura, rudimentos de historia y geografía y nociones generales de física e historia natural acomodados a las necesidades de la vida. El currículo femenino, tanto elemental como superior ${ }^{39}$, debía orientar a la niña a su función en la vida, por lo que se constituía de: Doctrina cristiana y nociones de Historia Sagrada, lectura y escritura, principios de gramática, principios de aritmética, labores propias de su sexo, elementos de dibujo aplicado a las mismas labores, rudimentos de historia y geografía de España y nociones de higiene doméstica. Más afortunadas fueron aquellas niñas que asistieron a escuelas incompletas mixtas ${ }^{40}$, pues a pesar de que la Ley establecía una división de sexos y de materias, en la práctica no se dio la separación física y, mucho menos, el maestro les enseñó aquellas nociones estrictamente femeninas, por lo que cursaron junto a sus compañeros el currículo masculino. De todos modos, en los Estados Escolares hemos constatado la preocupación y queja de los inspectores ante la escasa atención prestada en las escuelas femeninas a las labores propias de su sexo, ya fuera por la falta de interés, por parte de la maestra o por la escasez de material para ejecutarlas ${ }^{41}$.

El docente propiamente dicho era aquel que poseía un título que acreditaba su capacidad pedagógica, aunque en realidad, bajo esta designación se incluía a profesionales con una mínima formación intelectual. Los escolantes computados en el

37 Ley de Instrucción Pública de 9 de septiembre de 1857 , artículos $2^{\circ}$ y $3^{\circ}$.

38 Ley de Instrucción Pública de 9 de septiembre de 1857, artículo $4^{\circ}$.

39 Ley de Instrucción Pública de 9 de septiembre de 1857, artículo $5^{\circ}$.

40 "Únicamente en las Escuelas Incompletas se permitirá la concurrencia de los niños de ambos sexos, en un mismo local, y aún así con la separación debida". Ley de Instrucción Pública de 9 de septiembre de 1857 , artículo $103^{\circ}$.

41 "Que se procure que la escuela de niñas se provea del menaje preciso, a fin de que la profesora organice cuánto antes la enseñanza según el reglamento". AHUS. F.U. Ensino Primario, Caja 28, Porción $3^{\mathrm{a}}$, Ayuntamiento de Padrón, folio 2. 
Catastro y en el Diccionario fueron, en su gran mayoría, individuos con someros conocimientos de lectura, escritura, doctrina y aritmética elemental. La calidad de la enseñanza, por tanto, fue precaria ${ }^{42}$, pues es evidente que del grado de sabiduría del maestro dependía la efectividad de su instrucción ${ }^{43}$. Fueron comunes las quejas de los vecinos por la escasa capacitación de los docentes, al igual que por los malos tratos y usos empleados ${ }^{44}$. Uno de los casos más representativos sucedió en la villa de Padrón en la que el litigio entre los padres y las autoridades locales contra el maestro llegó a la Real Audiencia ${ }^{45}$. Por otra parte, la retribución del maestro es un indicador interesante para advertir su consideración social. La remuneración de los educadores era escasa, según el Catastro, el 50\% de los maestros cobraba menos de 100 reales al año, un $17,7 \%$ percibía entre 100 y 150 rs. y sólo un 5,5\% sobrepasaba los 600 rs. El salario del mentor era precario, muy escaso si lo comparamos con el de otros profesionales ${ }^{46}$, de ahí que fuese habitual que aquél realizase otras actividades complementarias ${ }^{47}$. El intervencionismo escolar de la segunda mitad del siglo XIX fue parejo a un intentó por parte de las autoridades competentes de vigilar y controlar la capacitación de sus maestros. En este sentido, en las visitas realizadas por los inspectores, tanto de las Juntas Locales como de las Juntas Provinciales, se buscó el saneamiento escolar tradicional denunciando y suplantando a aquellos maestros carentes de título o faltos de capacidades $^{48}$. De este modo, desde 1860 hasta 1875 la escuela privada más conocida

42 El aprendizaje era sucesivo, repetitivo y memorístico. La Estadística de 1846 nos dice que en un $15,4 \%$ de las escuelas se practicaba el método simultáneo y en un $84,6 \%$ el individual. Según los Estados Escolares de 1886 , en un $57,1 \%$ de los casos el método empleado era el individual y en un $42,9 \%$ mixto, individual y el simultaneo.

43 Había 17 maestros sin título frente a unos ocho titulados, según los datos de la Estadística de 1846.

44 Hemos contabilizado en un $48 \%$ de los casos quejas por el maltrato y abuso de la infancia. AHDS, Serie, Instrucción Pública, leg. 456, 459, 460.

45 En 1790 se llevó a cabo un pleito contra el maestro Juan Francisco Lema por las continuas palizas a los niños y, en concreto, por las graves heridas causadas a un niño de 13 años -“(...) el niño al no saber citar en latín la oración hízola en castellano por lo que fue golpeado duramente con una vara en la cabeza"-. Archivo del Reino de Galicia, Sección, Pleitos, Leg.9191/4.

46 En este sentido, el Catastro de la ensenada recoge el sueldo de otros profesionales: los herreros percibían entre 5-2 reales al día, los canteros 3 rs., los sastres 3 rs., los tejedores 2 rs., lo zapateros 2-3 rs., por lo que cualquiera de estos trabajadores ganaba mucho más al año que un maestro. Más llamativa es la diferencia salarial con los curtidores que podían ingresar hasta 2200 rs. al año. ARG, Catastro de Ensenada, Interrogatorio, libros 241, 242, 243, 244, 245, 246, 248, 251, 252, 253, 254, 255.

47 Generalmente eran individuos de mediana edad casados cuya actividad laboral les permitía dedicarse a la enseñanza y jóvenes, independientes o dependientes económicamente, que buscaban ingresos complementarios para casarse o formar su hogar. En otros casos, podían ser hombres de avanzada edad, con algún problema físico que contribuían a la economía familiar ejerciendo como maestros.

48 "Ello provocará que haya muchas deficiencias entre el maestro de la primera mitad del XIX y el de finales de éste. Al principio se trataba de un profesor sin preparación profesional, sin cultura, sabiendo el currículo de las tres erres, además de la doctrina cristiana y cantar. En ocasiones ha tenido que superar u 
como escuela de ferrado va a sufrir un importante receso, lo que va a interrumpir, en muchos casos, una tradición educativa que perduraba desde hacía más de un siglo. A partir de la segunda mitad de la década de los 70, la escuela de ferrado recuperará parte de su protagonismo, recobrando, en ocasiones, a su vieja estabilidad. A través de los informes de las Juntas Locales y por medio de los Estados Escolares, elaborados con el motivo de la visita del inspector provincial, obtenemos que el $4 \%$ de las escuelas eran de financiación privada frente a un 96\% de escuelas públicas de financiación mixta $^{49}$. La Ley de 1857 inauguraba el principio de gratuidad para aquellos padres que no pudiesen sufragar los gastos de la educación de sus hijos ${ }^{50} \mathrm{y}$, en la villa y tierra de Padrón, se acogieron a esta medida más de 284 niños y niñas ${ }^{51}$. Las dotaciones aumentaron considerablemente, aunque los sueldos siguieron siendo escasos, sólo un $5,9 \%$ de los docentes percibía más de 4000rs al año en 1862, un 27,8\% cobraba entre 2000 y 3000 reales y un 70,6\% ingresaba entre 1000 y 2000 rs. al año. Muy distintos eran los salarios ofertados en las escuelas privadas, en las cuales, los honorarios de los maestros apenas sobrepasaban los 400 reales anuales ${ }^{52}$. La dotación para material

pequeño examen para que las autoridades les extiendan el título pertinente, pero en muchos otros casos ni siquiera ha pasado por él y trabaja como intruso. Suelen ser maestros los zapateros, los sargentos cojos o mancos, muchos eran sacristanes". RUIZ BERRIO, J.: "El oficio del maestro en la sociedad liberal 18081839" en ESCOLANO BENITO, A. (dir.): Historia Ilustrada de la escuela en España. Dos siglos de perspectiva histórica. Madrid, 2006, pp. 122-123.

49 Ley de Instrucción Pública de 1857. Artículo1º 5. "Los establecimientos de Instrucción Pública se costearán: Primero. De las rentas que poseen y de las que lleguen a adquirir. Segundo. De las retribuciones que satisfagan los que reciban en ellos la enseñanza. Tercero. De lo que deben percibir, ya para su dotación, ya para completarla, de los presupuestos municipales, provinciales o del estado".

50 "La primera enseñanza elemental se dará gratuitamente en las escuelas públicas a los niños cuyos padres, tutores ó encargados no pudieran pagarla, mediante certificación expedida al efecto por el respectivo Cura párroco y visada por el alcalde del pueblo". Ley de Instrucción pública de 1857, art. $9^{\circ}$.

51 En 1862 no pagaban retribución por falta de posibilidades: 35 niños y 37 niñas en la Villa de Padrón, 16 niños en Carcacía, 8 niños/as en Herbón, 10 niños y 21 niñas en Rianxo, 8 niños en Asados, 24 niños en Leiro, 13 niños y 14 niñas en Rois, 15 niño/as en Aguas Santas, 20 niños/as en Buján, 14 niños/as en Herbogo, 12 niños/as en Leroño, 17 niños/as en Rivasar y 20 niños/as en Urdidle. AHUS. F.U. Ensino Primario, Caja 28, Porción 33 , Ayto. de Padrón , P.1, folio 2. AHUS. F.U. Ensino Primario, Caja 28, Porción $3^{\mathrm{a}}$, Ayto. de Padrón, folio 1. AHUS. F.U. Ensino Primario, Caja 28, Porción 3a, P.7: Carcacía, folio 1. AHUS. F.U. Ensino Primario, Caja 28, Porción $3^{\text {a }}$, Ayto. de Dodro, folios 1-2. AHUS. F.U. Ensino Primario, Caja 28, Porción 3a , P.9: Herbón, folio 2. AHUS. F.U. Ensino Primario, Caja 28, Porción $3^{\mathrm{a}}$, P.10: Rianxo, folio 1. AHUS. F.U. Ensino Primario, Caja 28, Porción 3a , P.9: Herbón, folio 2. AHUS. F.U. Ensino Primario, Caja 28, Porción 3a, P.11: Asasdos, folio 1. AHUS. F.U. Ensino Primario, Caja 28, Porción $3^{\mathrm{a}}$, P.12: Leiro, folio 1. AHUS. F.U. Ensino Primario, Caja 28, Porción 3ª P.14: Rois, folio 3. AHUS. F.U. Ensino Primario, Caja 28, Porción 3ª P.15: Rois, folio 2. AHUS. F.U. Ensino Primario, Caja 28, Porción 3 ${ }^{\mathrm{a}}$, P.16: Aguas Santas, folio 1. AHUS. F.U. Ensino Primario, Caja 28, Porción 3ª P.17: Buján, folio 1. AHUS. F.U. Ensino Primario, Caja 28, Porción 3a , P.18: Herbogo, folio 1. AHUS. F.U. Ensino Primario, Caja 28, Porción 3 ${ }^{\text {a }}$, P.19: Leroño, folio 1. AHUS. F.U. Ensino Primario, Caja 28, Porción 3a , P.20: Rivasar, folio 3. AHUS. F.U. Ensino Primario, Caja 28, Porción 3ª, P.21: Udilde, folio 1.

52 "La dotación de la escuela, no la hay por ser privada, y solo cuenta con la gratificación de los niños pudientes que ascenderá poco más o menos a 300 reales". AHUS. F.U. Ensino Primario, Caja 28, Porción $3^{\mathrm{a}}$, P.18: Herbogo, folio 2. 
escolar también era variable y fluctuaba entre 1100 y 250 rs, aunque, en la mayoría de los casos, la dotación se situaba entre los 300 y los 250 rs. Los inspectores, al percatarse de la escasez y mal estado del mobiliario escolar, recalcaron a las Juntas Locales la necesidad de vigilar y controlar la aportación dedicada a material, "que los maestros rindan oportunamente las cuentas documentadas de la inversión de fondos que se les libraron para material y con la censura de la Junta, se reúnan para la supresión o aprobación" 53 . En cuanto a la formación y capacidad del maestro hemos computado a través de los Estados Escolares que un 60\% de los maestros poseía título, un 25\% no poseía título pero contaban con la autorización pertinente de la Junta Provincial y un $15 \%$ no poseía título. Aunque la posesión o carencia de título apenas hacía variar las valoraciones que los inspectores hacían de los docentes. En 1862 los inspectores evaluaban cinco aspectos de los educadores: en primer lugar, su atención se centraba en los resultados de la educación y enseñanza, en segundo lugar, juzgaban la capacidad, la instrucción y la actitud del docente, en tercer lugar, el celo, posteriormente, la conducta $\mathrm{y}$, finalmente, averiguaban si estos tenían amonestaciones del párroco. En cuanto al primer aspecto, los resultados de la educación fueron pocos en un 57,8\% de los casos, muy pocos en un 5,3\% , regulares en un $15,8 \%$ y buenos en un $21,1 \%$. La capacidad, la instrucción y la actitud del maestro fue regular en un 72,2\% de los casos, buena en un 16,7\%, mediana en un 5,6\% y escasa en otro 5,6\%. En cambio, el celo mostrado por los escolantes fue poco y escaso en un $27,2 \%$ y en un $36,4 \%$ respectivamente, mediano en un $9,1 \%$ y bueno y muy bueno en un $18,2 \%$ y en un $9,1 \%$. Ninguno de ellos fue amonestado por las autoridades religiosas, aunque en algunas ocasiones los párrocos se vieron obligados a acudir al local de la escuela, ya fuera a petición de los padres o por una mayor vigilancia en el cumplimiento de los prefectos y de la doctrina cristiana; en todos los casos, la conducta se registró como buena.

La asistencia de los menores a la escuela no era constante a lo largo del año y su mayor presencia se concentraba en torno a determinadas épocas, sobre todo en aquellas en las que la capacidad laboral del niño en el hogar era menos necesaria ${ }^{54}$. El calendario escolar estaba definido y condicionado por la agenda agrícola y mercantil, por lo que generalmente la escuela permanecía abierta en los meses del invierno. La educación de los niños se realizaba en aquellos meses en los que la carga laboral era menor, pero las inclemencias del tiempo, la carencia de infraestructuras y la mala

53 AHUS. F.U. Ensino Primario, Caja 28, Porción 3a , Ayuntamiento de Rianxo, folio 2. AHUS. F.U. Ensino Primario, Caja 28, Porción 3a ${ }^{\mathrm{a}}$, Ayuntamiento de Dodro, folio 1. AHUS. F.U. Ensino Primario, Caja 28, Porción $3^{\text {a }}$, Ayuntamiento de Rois, folio 1. AHUS. F.U. Ensino Primario, Caja 28, Porción $3^{\text {a }}$, Ayuntamiento de Teo, folio 2. AHUS. F.U. Ensino Primario, Caja 28, Porción 3ª Ayuntamiento de Padrón, folio 2.

54 La media de asistencia de los niños a las escuelas primarias en la actual provincia de A Coruña, según la estadística de 1870 era: de menos de tres meses en un $12.9 \%$ de los casos, entre tres y seis meses era del $16,5 \%$, entre seis y nueve meses era del $29,5 \%$ y entre nueve y doce meses era del $41,1 \%$. 
comunicación limitaban aún más el aprendizaje. No debemos olvidar que este aspecto es fundamental ya que “(...) el calendario y el horario académico, con sus alternancias de trabajo y asueto, han configurado no sólo una estructura de la institución educativa, sino a la infancia misma como hecho cultural"55. Los maestros plasmaron la asistencia escolar en los Estados Escolares, aunque, sus previsiones, infladas en diversas ocasiones, fueron corregidas por los inspectores provinciales, quienes llevaron buena cuenta del número de alumnos que asistían a las clases ${ }^{56}$. La información más interesante aparece recogida en los Estados posteriores a 1886, pues hasta este momento los maestros conocían la fecha de la visita con mucho tiempo de antelación, lo que les permitía acondicionar y aleccionar a los niños para obtener mejores resultados en el reconocimiento del visitador. Sea como fuere, la media de asistencia escolar en la villa y tierra de Padrón en 1862 era de un 68,04\%, aunque la asistencia fue tremendamente oscilante. Así pues, entorno a un 57,9\% de los casos la asiduidad era igual o superior al 70\% del total de alumnos, en un 31,6\% estaba entre el $50 \mathrm{y}$ el $70 \%$ del total y en un $15 \%$ de los casos la presencia era inferior a la mitad de los alumnos matriculados, por lo que podemos sostener que las escuelas del valle del Ulla estaban bastante concurridas, aunque con algunas advertencias: "la concurrencia a la escuela es tan irregular que no es posible fijar un término medio en el número que asisten diariamente, pues según las tareas del campo son más o menos importantes, así se nota en las mismas épocas más o menos asistencia de los niños a la escuela (...)" ${ }^{\text {57 }}$. A partir del Real Decreto de 23 de febrero de 1883 los maestros tuvieron la obligación de llevar constancia de la asistencia infantil diaria ${ }^{58}$, situándose la media alrededor de los 84-94 días frente a un total de 120 días lectivos ${ }^{59}$, lo que supone unas cifras un tanto paradigmáticas, puesto que según estas previsiones un niño sólo faltaría entre 26 y 37 días en un año escolar. Esta duda se hace más acuciante al consultar

55 ESCOLANO BENITO, A.: "El orden del tiempo. Almanaques y horarios para la escuela" en ESCOLANO BENITO, A. (dir.): Historia Ilustrada de la escuela en España. Dos siglos de perspectiva histórica, Madrid, 2006, pp. 122-123.

56 La maestra de la escuela pública elemental incompleta de Dodro, Bernarda Cortés, establecía el número de alumnas matriculadas era de 68 , aunque advertía que el grueso de las que concurrían habitualmente variaba según la urgencia de las labores del campo, por lo que su asistencia rondaba las 30 o 40 niñas, a lo que el visitador corrigió anotando que en el día de la visita sólo acudieron 10 de ellas. AHUS. FU. Ensino Primario, Caja 28, Porción 3a , P.3: Laiño, folio 1.

57 Anotación realizada por D. Joaquín María Domínguez y Campos, docente de la escuela pública elemental completa de niños. AHUS. F.U. Ensino Primario, Caja 28, Porción 3a, P. 14: Rois, folio 3.

58 Esta obligación ya estaba registrada en la Ley de 1857 pero los datos no se han conservado.

59 El "curso escolar" en el último tercio del XIX duraba entorno a unos 5-6 meses. AMP, Sección: Educación, leg. 498. "Los estudios de la primera enseñanza no están sujetos a determinado número de cursos: las lecciones durarán todo el año, disminuyéndose en la canícula el número de horas de clase”. Ley de Instrucción Pública de 9 de septiembre de 1857, artículo $10^{\circ}$. 
los Estados de 1776 y de 1886, en los cuales la asistencia media en las escuelas no superaba el $66 \%{ }^{60}$.

El horario estuvo condicionado y supeditado a las horas de luz ${ }^{61}$. El Reglamento de 1838 dispuso que la duración de las clases fuera de seis horas diarias -tres horas en la mañana y tres en la tarde- y más tarde esta fue confirmada por la Ley de Instrucción de 1857. Las Juntas Locales fueron, en última instancia, las encargadas de fijar el horario y, según hemos comprobado, éstas se ciñeron a los presupuestos de la ley ${ }^{62}$, con dos salvedades constantemente denunciadas por los inspectores, que los jueves por la tarde debía haber escuela y que los días de media fiesta también. La distribución semanal de las materias se realizaba del siguiente modo: "las secciones de Religión y Moral seis horas y media, las de lectura nueve, de escritura cuatro y media, de Historia Sagrada una y media, las de Gramática dos y media, las de Aritmética, Sistema Métrico y agricultura una, las de Ortografía, teoría y práctica al dictado una, las de urbanidad media, las de Geometría una e igual tiempo en las de Geografía e Historia y una a la de comercio"63. En lo que se refiere a la distribución del programa educativo femenino: "en la semana se invierten en lectura diez y dos horas, en escritura seis horas las de esta sección, en doctrina moral dos horas, en aritmética dos, en calceta tres, en costura tres y en bordado otras tres" ${ }^{\prime 64}$.

Pero si algo definió a las escuelas rurales del siglo XVIII y XIX fue su precariedad físico-espacial que, de algún modo, condicionó el desarrollo psicomotor infantil. Hasta el siglo XIX no podemos relacionar la escuela con un lugar acondicionado para la enseñanza ${ }^{65}$ y, aún cuando esta disponga de un local específico, sus condiciones

60 AHUS. F.U. Ensino Primario, Caja 28, Porción 6a, P.2: Rois, folio 1. AHUS. F.U. Ensino Primario, Caja 28, Porción 6a, P.2: Rois, folio 1. AHUS. F.U. Ensino Primario, Caja 28, Porción 6a , P.3: Teo, folio 1. AHUS. F.U. Ensino Primario, Caja 28, Porción 6a , P.4: Cacheiras, folio 1. AHUS. F.U. Ensino Primario, Caja 28, Porción 8a , Ayuntamiento de Rianxo, folio 1. AHUS. F.U. Ensino Primario, Caja 28, Porción 8a, P.1: Leiro, folio 2. AHUS. F.U. Ensino Primario, Caja 28, Porción 8a , P.2: Taragoña, folio 1.

61 Narciso de Gabriel ha establecido una media de unas siete horas diarias para finales del siglo XIX. GABRIEL, N. de: Leer, escribir y contar: escolarización popular y sociedad en Galicia (18751900), A Coruña, 1990, p. 277.

62 En este sentido, en 1865 los padres de las niñas asistentes a la escuela elemental incompleta de la villa de Padrón presentaron una queja a la Junta Local por el poco celo y el escaso cumplimiento de los horarios por parte de la profesora, quien abría la escuela dos horas tarde, lo que obligaba a las muchachas a esperar a la lluvia. AMP. Sección, Educación, leg. 497.

63 Este ejemplo del empleo semanal del tiempo de la escuela elemental incompleta de Herbón es interesante porque se trata de una escuela mixta y en su programación podemos observar como no aparece señalado un programa alternativo para las niñas, por lo que ellas cursarían el currículo masculino. AHUS. F.U. Ensino Primario, Caja 28, Porción 3a , P.9: Herbón, folio 2.

64 Escuela pública elemental incompleta de niñas de Laiño. AHUS. F.U. Ensino Primario, Caja 28, Porción $3^{\mathrm{a}}$, P. $3^{\mathrm{a}}$ : Laiño, folio 1.

65 "El edificio escolar debía ser configurado, como la actividad educativa, de un modo específco, definido y propio, independiente de cualquier otro y adecuado a tal fin. Ello implicaba no sólo su ais- 
pedagógicas seguirán siendo cuestionables ${ }^{66}$. Los centros de instrucción pública disponían generalmente de una ubicación física, en este sentido, entorno al 42\% de las dotaciones registradas entre finales del siglo XVIII y la primera mitad del siglo XIX, estipulaban la creación de un espacio docente, aunque esta misiva no siempre se cumplió. En el caso de las privadas, la educación se efectuaba en un edificio cedido por los padres o vecinos para el asentamiento del maestro y, en otras, se ubicaba en el propio hogar del instructor. A partir de mediados del XIX la normativa oficial fijó la dotación o creación de una escuela como el proporcionar de un lugar físico dispuesto o preparado para la enseñanza ${ }^{67}$, por lo que en las diversas feligresías se constituyó un local para tal fin. Antonio de la Iglesia en 1862 fue conciente de la precariedad y falta de acondicionamiento de muchas de estas instalaciones por lo que dejó constancia, en los Estados y en las actas de las reuniones de las Juntas Locales, de la necesidad de reformar y preparar las escuelas para un mejor y más saludable desarrollo educativo. Algunas de las quejas presentadas hicieron referencia a la insalubridad y suciedad del local, pues en muchas ocasiones se trataba de una angosta estancia con apenas luz y ventilación en los cuales la humedad llenaba el ambiente con su vetusto aroma ${ }^{68}$. Otras veces, la reclamación estaba relacionada con la ubicación del local, por ser esta poco adecuada para la madurez civil y moral de los niños ${ }^{69}$. Al igual que sucedía con

lamiento y separación, sino también su identificación física, visual y arquitectónica, como tal." VIÑAO FRAGO, A.: "Templos de la patria, templos del saber. Los espacios de la escuela y la arquitectura escolar" en ESCOLANO BENITO, A. (dir.): Historia Ilustrada de la escuela en España. Dos siglos de perspectiva histórica. Madrid, 2006, p. 47-48.

66 Las descripciones de las escuelas municipales de la segunda mitad del XIX nos muestran unos locales escasamente habitables y totalmente carentes de sentido instructivo-pedagógico: La escuela municipal de Padrón se hallaba en el piso inferior a la cárcel. La escuela de Carcacía se encontraba con el techo y el piso en un estado lamentable, por lo que en los días de mucha lluvia, los niños debían desistir de su asistencia. La escuela de Rivasar apenas tenía ventilación por lo cual el visitador denunció su carácter insano. AMP, Sección, Educación, leg. 497.

67 Los locales fueron de tipología variada, podían ser locales alquilados, locales “públicos”, locales cedidos o creados por fundación o locales privados.

68 "El local de la escuela es muy reducido y oscuro. No tiene sino una ventana con un pequeño tragaluz. (...) sólo tiene de longitud cinco metros y treinta y ocho centímetros: latitud, tres metros cuarenta y cuatro centímetros. Y su altura es la de dos metros sesenta y cinco centímetros. (...) siendo introducidas las aguas por la pared de este lado, causando por ello perjuicio de consideración”. AHUS. F.U. Ensino Primario, Caja 28, Porción 3", P.1: Dodro, folio 2. "Situación regular, pero local sin vidrieras en las ventanas y sin luz". AHUS. F.U. Ensino Primario, Caja 28, Porción 3a, P.7: Carcacía, folio 1. "Conforme pero insalubre el salón y además triste: cosa extraña en verdad, pudiendo disponer de buen local en cualquier otro paraje de este convento”. AHUS. F.U. Ensino primario, Caja 28, Porción 3a , P. 9: Herbón, folio 1.

69 "El paraje en que se halla situada la escuela no es el más apropósito para esta clase de establecimientos, por no reunir las condiciones que deben tener, siempre que nos sea posible elegir su situación: esta es una posición poco ventilada, muy pública, y lo que es peor, lindando por el norte con un establecimiento de carnes o carnicería, en que la concurrencia de gentes, la muerte alevosa de las reçes y las palabra indecorosas que a cada poco suelen proferir la clase de gente que desempeña el encargo, son cosas que nada favorecen a la moral de los niños”. AHUS. F.U. Ensino Primario, Caja 28, Porción 3ª, P.14: Rois, 
el salón de clase y la situación, el moblaje y su posición fue también controlado ${ }^{70}$. Los muebles, en muchos casos, se reducían a un conjunto de bancos y mesas para los niños, una silla y una mesa para el profesor y un cuerpo de carpintería dónde guardar libros, cartillas, pizarrines, etc. Es difícil establecer una valoración de un aspecto tan poco preciso como el acondicionamiento de la escuela, porque su evaluación es poco cuantificable. En términos generales, los locales fueron catalogados como: buenos en un $10,5 \%$ de los casos, bastante buenos en un $15,8 \%$, regulares o bastante regulares en un $42,1 \%$, y malos o poco adecuados en un $31,6 \%$. Los visitadores, no dejan lugar a duda, el estado del mobiliario era viejo o muy usado y, aunque, su disposición no solía ser la más correcta, este hecho no era considerado como tan grave al poder ser rectificado in situ. Ellos juzgaron el estado, la composición y la utilidad del moblaje siendo sus estimaciones muy buenas o buenas en un $15 \%$ de los casos, bastante buenas en un $25 \%$, regulares o bastante regulares en un 33,3\% y malas en el $22,2 \%$. Algunas de las apreciaciones llevadas a cabo por el inspector deben ser matizadas puesto que su función era la de valorar el estado de las escuelas tomando como referencia un edificio tipo que en muy escasas ocasiones se localizaba en el mundo rural, de este modo, podemos encontrarnos con valoraciones bastante negativas aunque debemos ser conscientes de que en un contexto rural su estado y acondicionamiento era adecuado ${ }^{71}$. Del mismo modo, también hemos consultado otros ejemplos en los que los enseres eran variados y sus piezas destacaban por la nobleza de sus materias primas, como es el caso de la escuela completa y ampliada de niños de Padrón ${ }^{72}$ que poseía: un escritorio para el profesor con una buena escribanía de metal, un sillón, seis sillas, un armario de castaño dividido, dos tablones para los ejercicios de aritmética y geometría, un cuadro de la Reina con su marco dorado, un cuadro del sistema métrico, nueve cuerpos de carpintería de madera de pino, mesas de escribir, bancos, ocho templadores de asta, mapas geográficos, carteles para los ejercicios de lectura, cuadros con la distribución del tiempo y del trabajo, carteles con máximas morales y un cartel con el sistema de pesos y medidas.

folio 1. "El lugar donde se halla situada la escuela es impropio, para el objeto, por estar lindando al oriente con el cementerio de la iglesia parroquial, falto de ventilación y asombrado por el edificio de la Iglesia". AHUS. F.U. Ensino primario, Caja 28, Porción 3 ${ }^{\mathrm{a}}$, P. 16: Aguasantas, folio 1.

70 El reglamento de Escuelas de Instrucción Primaria Elemental de 1838, reguló con detalle el menaje y útiles, así como condiciones físicas que debía poseer un aula y, posteriormente, la Ley Moyano los ratificó.

71 Don Joaquín María Domínguez y Campos denunciaba la mala ubicación de la escuela pública elemental completa de niños de Rois, en cambio, admitía que el estado y condiciones del local eran óptimos: "el estado del edificio y sus dependencias son buenas, si tenemos en cuenta que en todo el radio del distrito escolar, es probable que no se halle un local más apropiado al objeto respecto a su construcción". AHUS. F.U. Ensino primario, Caja 28, Porción 3a , P. 14: Rois, folio 1.

72 AHUS. F.U. Ensino primario, Caja 28, Porción 3a , P. 4: Padrón, folio 1 y 2. 
El último aspecto, al cual debemos hacer referencia, está relacionado con el material utilizado para la docencia ${ }^{73}$. La ley del 1857 fijó un número de materiales y libros básicos que toda escuela debía poseer ${ }^{74}$, así aparecen sistemáticamente los mismas obras y los mismos útiles ${ }^{75}$, aunque su propiedad fuera del local o del docente. Fueron común denominador en las escuelas del Ulla, tal y cómo lo establecía la ley, los ejemplares de La escuela de Instrucción Primaria o colección de todas las materias que comprende la Instrucción Primaria por Ricardo Díaz de Rueda, la Aritmética de José Mariano Ortega y Vallejo, el Catecismo histórico o. compendio de la historia sagrada y de la doctrina cristiana para instrucción de los niños, con preguntas y respuestas, y lecciones seguidas para enseñarlas en las escuelas por el abad Claude Fleuri, los Cuadernos Litografiados de Araujo, los Métodos de Lectura de José Manuel Naharro y el Catecismo y exposición breve de la doctrina cristiana de Jerónimo Martínez Ripalda o las Cartillas de Doctrina Cristiana por Pedro Gaspar Asteste, más conocidas cómo el Catecismo de Astete. Aunque hemos localizado otros trabajos que ilustraban y guiaban a los maestros y maestras en el aprendizaje infantil como: las Cartillas Agrarias de Alejandro Olivan, las Obras de Urbanidad por Jacinto Salvá, los Compendios de Gramática Castellana por la Academia, el Catecismo de Doctrina Cristiana por D. José García Mazo, la Biblia de los Niños por D. Antonio Alverá Delgrás, además de los habituales cuadros o carteles del Sistema Pitagórico, del Sistema de Pesos y Medidas, silabarios y de los mapas geográficos de España.

A modo de conclusión, podemos decir que el panorama educativo del bajo Ulla, presentó un desarrollo positivo, que si bien fue lento y desigual, también fue constante y ascendente en el tiempo. El sistema de aprendizaje repetitivo y memorístico, la falta de un lugar acondicionado para la docencia, la carencia de infraestructuras y material y la escasa formación de los maestros fue causa y efecto de un retraso

73 Manuel-Reyes García Hurtado ha realizado una excelente síntesis de los principales autores y obras que reflexionaron sobre la instrucción primaria en el siglo XVIII. GARCÍA HURTADO, M.-R.: "Reflexiones sobre algunos textos destinados a enseñar a leer y escribir en España entre 1700 y $1780 "$ Obradoiro de Historia Moderna, $\mathrm{n}^{\mathrm{0}}$ 13, 2004, pp.7-38.

74 "Unos mismos libros de texto señalados por el Real Consejo de Instrucción Pública regirán en todas las escuelas". Ley de Instrucción Pública de 9 de septiembre de 1857 . Artículo $1^{\circ}$, punto $4^{\circ}$.

75 "El uso del llamado sistema individual en los establecimientos tradicionales, que no exigía la utilización simultánea del mismo manual por los alumnos y que permitía con un solo libro, propiedad de la escuela o del maestro, enseñar sucesivamente a cada uno de los niños, no demandó el uso personal del texto. La progresiva, aunque lenta, difusión de la enseñanza simultánea terminó por favorecer el desarrollo de una industria editorial asociada a las publicaciones didácticas, que se sirvió además de los avances técnicos que en el siglo XIX empezaron a renovar el sector de las artes gráficas". ESCOLANO BENITO, A.: "La codificación de la primera manualística" en ESCOLANO BENITO, A. (dir.): Historia Ilustrada de la escuela en España. Dos siglos de perspectiva histórica. Madrid, 2006, pp. 219-239. 
intelectual endémico en la Galicia rural del siglo XVIII y XIX. Sin embargo, no debemos despreciar o infravalorar los aportes de la enseñanza de aquellos siglos pues, de una manera o de otra, fueron los principales agentes culturales y de civilización de la Galicia campesina y agrícola del Antiguo Régimen. En este sentido, seria muy interesante analizar el influjo de la educación en la alfabetización de las gentes de la villa y tierra de Padrón, aunque debemos ser conscientes, como bien afirma O. Rey Castelao $^{76}$, de que la identificación entre escolarización y alfabetización no es del todo correcta, ya que la escolarización no siempre fue factible y eficaz y la instrucción podría suplirse con otras formulas -educación informal y no formal-.

76 REY CASTELAO, O.: Libros..., p. 48. 
Tabla 1. Los maestros de Instrucción Primaria en 1753

\begin{tabular}{|c|c|c|c|}
\hline Feligresía & Maestros & Sueldo & Vecinos \\
\hline Baamonde & No especifica & - & 64 \\
\hline Calo & $\begin{array}{l}\text { Pedro Aretea } \\
\text { Mateo Pérez } \\
\text { Gregorio do Monte }\end{array}$ & $\begin{array}{l}50 \text { rs. } \\
50 \text { rs. } \\
-\end{array}$ & 355 \\
\hline Cacheiras & Antonio Fernández & - & 298 \\
\hline Carcacía & Gregorio García de Castro & 60 rs. & 254 \\
\hline Cruces & Lorenzo Lemos & $100 \mathrm{rs}$. & 314 \\
\hline Laiño & Julián de Ocampo & 60 rs. & 484 \\
\hline Padrón & $\begin{array}{l}\text { Andrés Francisco Montoto } \\
\text { Juan Faveiro } \\
\text { Juan Antonio Senra }\end{array}$ & $\begin{array}{l}600 \text { rs. } \\
50 \text { rs. } \\
50 \text { rs. }\end{array}$ & 954 \\
\hline Reyes & $\begin{array}{l}\text { Felipe García } \\
\text { Antonio Fernández }\end{array}$ & $\begin{array}{l}70 \mathrm{rs} . \\
36 \mathrm{rs} .\end{array}$ & 185 \\
\hline Rianxo & $\begin{array}{l}\text { D. Joseph Alonso de } \\
\text { Castro }\end{array}$ & 150 rs. & 436 \\
\hline Rois & $\begin{array}{l}\text { Joseph Antonio Benduga } \\
\text { Fernando Pérez }\end{array}$ & $\begin{array}{c}60 \mathrm{rs} . \\
-\end{array}$ & 262 \\
\hline Sorrivas & $\begin{array}{l}\text { Juan Guenz } \\
\text { Andrés Canvalleira }\end{array}$ & $\begin{array}{c}60 \mathrm{rs} . \\
-\end{array}$ & 156 \\
\hline Teo & Domingo de la Iglesia & 1 rs. por niño/día & 129 \\
\hline Urdilde & Josep Canvalleira & 80 rs. & 229 \\
\hline
\end{tabular}

Fuente: Tabla elaborada a partir de los datos recopilados en el Interrogatorio del Catastro (1753). ARG, Catastro de Ensenada, Interrogatorio, Libros Personales y Reales, libros 241, 242, 243, 244, 245, 246, 248, 251, 252, 253, 254, 255.

\section{Mapa 1. La red escolar en 1753}

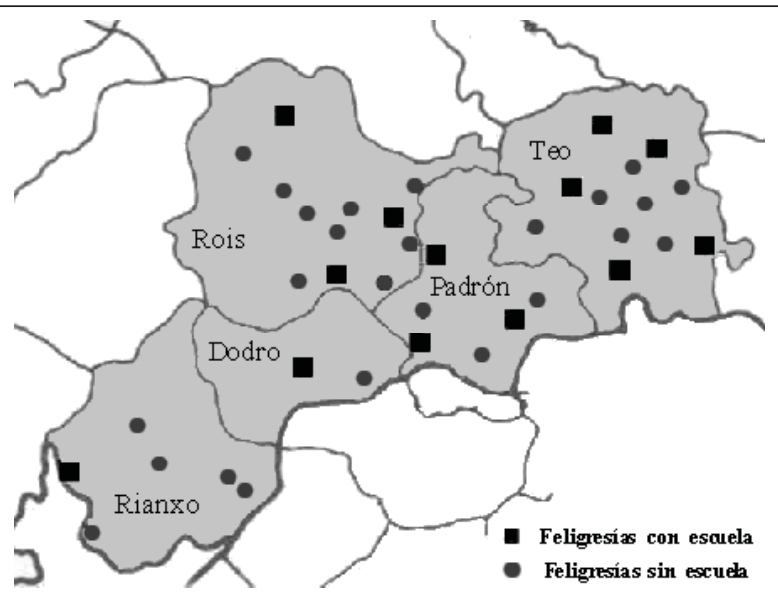

Fuente: ARG, Catastro de Ensenada, Interrogatorio, Libros Personales y Reales, libros 241, 242, 243, 244, 245, 246, 248, 251, $252,253,254,255$ 
Tabla 2. Las Escuelas Elementales en 1846

\begin{tabular}{|l|c|c|c|}
\hline \multicolumn{1}{|c|}{ Feligresía } & Escuelas & Escolares & Vecinos \\
\hline Asados & 1 & 30 & 80 \\
\hline Buján & 1 & 36 & 138 \\
\hline Cacheiras & 1 & 96 & 217 \\
\hline Calo & 2 & 96 & 314 \\
\hline Carcacía & 1 & 30 & 108 \\
\hline Dodro & 1 & 30 & 419 \\
\hline Herbogo & 1 & 49 & 123 \\
\hline Hermedelo & 1 & 23 & 94 \\
\hline Laíño & 1 & 33 & 102 \\
\hline Laiño & 1 & 30 & 270 \\
\hline Leiro & 1 & 26 & 200 \\
\hline Leroño & 1 & - & 133 \\
\hline Luou & 1 & 70 & 118 \\
\hline Padrón & 3 & 228 & 1218 \\
\hline Rianxo & 2 & - & 393 \\
\hline Rivasar & 1 & 40 & 129 \\
\hline Rois & 1 & - & 190 \\
\hline Sorrivas & 1 & 38 & 152 \\
\hline Taragoña & 1 & 74 & 260 \\
\hline Teo. & 1 & - & 122 \\
\hline Urdilde & 1 & 64 & 196 \\
\hline
\end{tabular}

Fuente: Tabla elaborada a través del Diccionario de P. Madoz.

Mapa 2. La red escolar en 1846

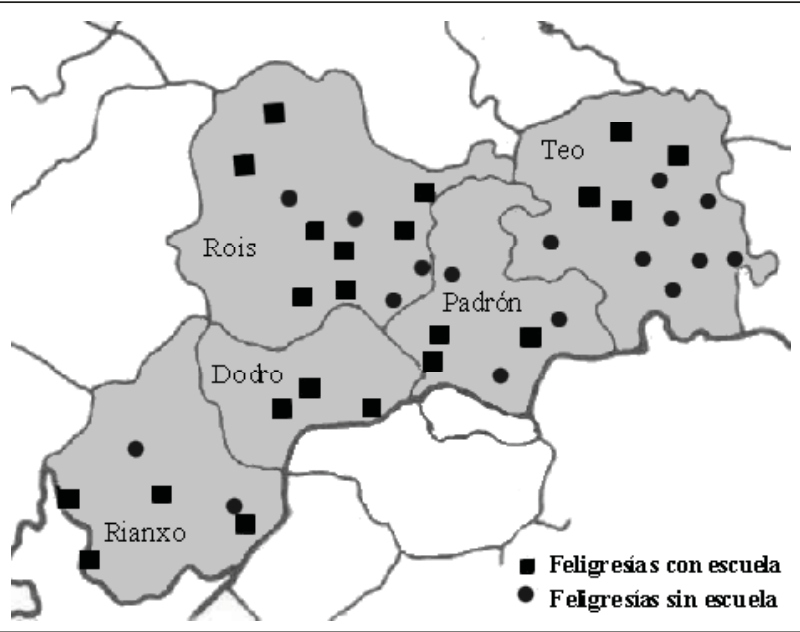

Fuente: Diccionario Geográfico-estadístico-histórico de España y sus posesiones de Ultramar de P. Madoz. 
Tabla 3: Las escuelas de educación primaria en 1862-1876

\begin{tabular}{|c|c|c|c|}
\hline Feligresía & Escuelas & Escolares & Asistencia \\
\hline Aguas Santas & 1 & 34 & $36,8 \%$ \\
\hline Asados & 1 & 36 & $100 \%$ \\
\hline Buján & 1 & 64 & $58,6 \%$ \\
\hline Cacheiras & 2 & 120 & $80 \%$ \\
\hline Calo & 2 & 108 & $64,85 \%$ \\
\hline Carcacía & 1 & 60 & $79,2 \%$ \\
\hline Costa & 1 & - & - \\
\hline Cruces & 1 & 80 & $68,8 \%$ \\
\hline Dodro & 1 & 65 & $76,9 \%$ \\
\hline Herbogo & 1 & 44 & $62,5 \%$ \\
\hline Herbón & 1 & 76 & - \\
\hline Laíño & 2 & 160 & $38,6 \%$ \\
\hline Leiro & 1 & 30 & $80 \%$ \\
\hline Leroño & 1 & 60 & $83,3 \%$ \\
\hline Luou & 1 & 80 & - \\
\hline Oza & 1 & 76 & - \\
\hline Padrón & 3 & 224 & $79,9 \%$ \\
\hline Rianxo & 2 & 160 & $71,9 \%$ \\
\hline Rivasar & 1 & 107 & $74,8 \%$ \\
\hline Rariz & 1 & 72 & - \\
\hline Reyes & 1 & 44 & - \\
\hline Rois & 2 & 105 & $69,4 \%$ \\
\hline Seira & 1 & - & - \\
\hline Sorrivas & 1 & - & - \\
\hline Taragoña & 1 & - & - \\
\hline Teo & 1 & 52 & - \\
\hline Urdilde & 1 & 56 & $44,7 \%$ \\
\hline
\end{tabular}

Fuente: Tabla elaborada a partir de los Estados Escolares 1862-1876. AHUS. F.U. Ensino primario, Caja 28, Porción 3a ,y $6^{0}$.

Mapa 3: La red escolar en 1862-1873

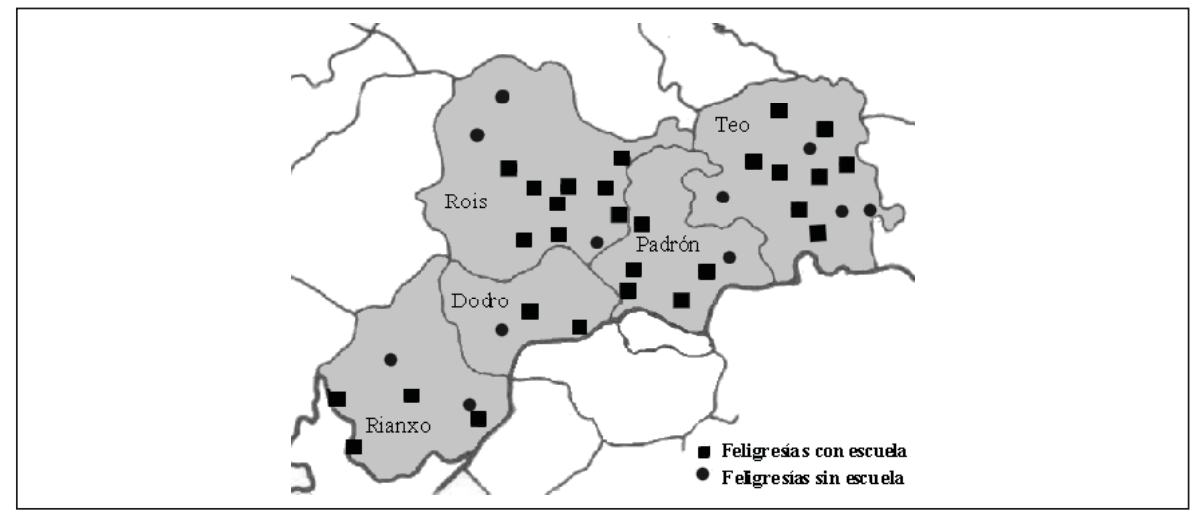

Fuente: Mapa elaborado a partir de las informaciones contenidas en los Estados Escolares de 1862-1876. AHUS. F.U. Ensino primario, Caja 28, Porción $3^{\mathrm{a}}$, $6^{0}$. 